\title{
THE EMERGENCE OF FUNCTIONAL CATEGORIES IN THE HISTORY OF ENGLISH: ONTOGENY AND PHYLOGENY IN LANGUAGE
}

\author{
FUYO OSAWA \\ Hosei University
}

\begin{abstract}
This paper claims that the drastic change in the English language can be better explained in terms of the emergence of functional categories, assuming that language shifts from a lexical-thematic stage to a functional stage over time. The process of first language acquisition of English children also embodies this shift. Old English is supposed to have lacked functional categories such as DP, TP and CP. Many syntactic phenomena related to these functional categories were absent in Old English. They were made possible later after these functional categories emerged. First language acquisition is also described as the process of acquiring functional categories. This parallelism between ontogeny and phylogeny is attested in the relation between aspect and tense.*
\end{abstract}

Keywords: ontogeny, phylogeny, acquisition, aspect, tense

\section{Introduction}

This paper argues that the drastic change in the English language over a short period of time can be better explained in terms of the emergence of functional categories. The background assumption is that languages typically start as lexical-thematic without any functional categories (i.e. typically DP, TP/IP, CP, or whatever); this means that a given language deploys the four lexical categories $(\mathrm{N}, \mathrm{V}, \mathrm{A}$, and $\mathrm{P})$, i.e. content words in traditional

* This paper is based on the symposium presentation I made at the 26th Conference of the English Linguistic Society of Japan held at University of Tsukuba on November 16,2008 . I would like to thank the audience at the symposium for their invaluable comments. I am greatly indebted to anonymous $E L$ reviewers for their useful comments and suggestions, which have had an influence on the organization of this paper. All remaining errors and inadequacies are my own. This work is supported by Grant-in-Aid for Scientific Research of Japan Society for the Promotion of Science No. 21520516. 
terms, and their phrasal projections, (NP, VP, AP, and PP). ${ }^{1} \quad$ Then, over a period of time, a new functional category is introduced in a given language. The emergence of a new functional category is the characteristic mark of a transition from one historical stage to the next (cf. Osawa (2003a)).

I claim that the history of English is a good instantiation of this shift from a lexical to a functional stage, and the process of first language acquisition of English children also embodies this shift. This view is in sharp contrast to the view that all languages have the same set of functional categories at any stage of their development. However, the diachronic shift of English from a lexical to a functional stage is also supported by Gelderen (2004):

(1) In work such as Cinque (1999), all languages have the same array of functional categories. What I hope to have shown above is that this is not the case. ... Some languages are more 'lexically-oriented', i.e. towards the VP, and others more 'grammaticallyoriented', i.e. towards the IP.

(Gelderen (2004: 252))

As Muysken (2008: 84) suggests, Gelderen (2004: 252) argues that Old English (hereafter OE) is more lexically-oriented, and Modern English more grammatically-oriented, and the development of English can be viewed in terms of grammaticalization.

The notion of lexical-thematicity is most important in my discussion. This notion is defined by Radford (1990) for child grammars at the early multiword stage:

(2) $\ldots$ the earliest (i.e. early multi-word stage) structures produced by young children are lexical-thematic structures (i.e. structures in which all constituents belong to lexical categories, and in which all sister constituents are thematically inter-related).

(Radford (1990: 46))

(3) $\ldots$ thematic constituents typically belong to lexical categories, i.e. Nouns, Verbs, Adjectives, Prepositions and their projections, NP, VP, AP, PP, whereas non-thematic constituents belong to functional categories (i.e. Determiners, Auxiliaries, Complementizers and their projections. (cf. Abney (1987), Radford (1990: 46)) Then, only words belonging to lexical categories are thematic, while functional constituents would always be non-thematic. It would also be the

1 There is a debate about the exact status of prepositions. I suggest that prepositions are located halfway between lexical and functional categories. 
case that nominal arguments are theta-marked only by lexical, not by functional, constituents (Radford (1990: 47)). I claim that this notion of lexicalthematicity applies to earlier languages, too.

In order to verify my claim, I take up the emergence of functional categories in English, and argue that there are syntactic parallels between diachronic changes and first language acquisition in terms of functional category emergence. I argue that this parallelism between ontogeny and phylogeny is also attested in the relation between aspect and tense.

\section{English in History}

\subsection{Absence of DP}

I claim that in $\mathrm{OE}$ a functional category $\mathrm{D}$ is absent, that is, $\mathrm{OE}$ has only NPs, and hence, the related syntactic phenomena are absent. Later NP develops into DP via the emergence of a functional category D within former nominal structures.

In OE, we can find examples of bare NPs in which determiners would be required in Present-day English (hereafter PDE).

(4) $\mathrm{He}$ gefeng pa fetelhilt ... yrringa sloh He (The warrior) grasped that linked hilt-ACC angrily stroke pæt hire wið halse heard grapode banhringas bræc that her with neck-Dat strongly grasped vertebras-ACC broke bil eal Jurhwod fægne flæschoman sword-Nom all went through fated body-ACC ... 'He (the warrior) drew a linked hilt ... and brought it down angrily to take her by the neck strongly, breaking the bones; the sword went through the death-doomed body'

(Beowulf 1563-1569 Klaeber (1950: 59))

The examples of bare nominals above banhringas and bil in argument positions are especially crucial, since they definitely need determiners in PDE. These examples clearly show that OE had no syntactic D-system, contrary to PDE.

The possible counter-argument against this claim is that there were two demonstratives se (seo/pcet), pes (bis/peos), which functioned as determiners. We must be careful when we decide whether some lexical item in a given language is qualified as functional category or not. As Abney (1987: 64f.) argues, the nature of functional categories is multi-faceted. None of those properties proposed by Abney are crucial in deciding whether an element is lexical or functional. Therefore, I claim that the presence of syntactic ef- 
fects which are dependent on the presence of a relevant functional category in a given language is crucial.

OE lacks the syntactic effects related to the presence of DP, however. The demonstratives in $\mathrm{OE}$ mentioned above have descriptive content, and can be used independently without complements. The data below clearly shows that demonstratives in $\mathrm{OE}$ are not a functional $\mathrm{D}$.

(5) Se wæs feorða eac fiftegum from Augusto $\mathrm{He}$ was forth also fifty from Augustus 'He was the fifty-fourth from Augustus.'

(Bede 54. 22-4, Ono and Nakao (1980: 309)) The absence of a D-system is also supported by the syntactic evidence, i.e. the lack of anaphor binding in OE. In OE, personal pronouns were used as anaphors and therfore the meaning of the sentence "He killed him" was indeterminate as to whether the object referred to the subject or not. Since a D-system is the locus of binding properties of nominals and pronouns, this absence will follow easily if we assume the lack of a D-system in OE.

(6) Ic on earde bad / .. ne me swor fela

I on earth was around ... not me-Dat swore many aða on unriht

oaths wrongfully

'I was around on earth ... I never perjured myself.'

(Beowulf 2736-2738, Gelderen (2000: 34))

The non-presence of a D-system in OE, and its subsequent appearance is also supported by the absence of group genitive constructions. The group genitive is a construction where the genitive ending $-' s$ is apparently affixed to the last element of a noun phrase.

(7) [DP [DP the king of England] [D' [D 's] [NP hat]]]

Genitive -'s in PDE is supposed to be a head determiner according to the DP analysis. This group genitive construction is not observed in OE. Furthermore, in $\mathrm{OE}$, the case-assigning "dummy" preposition of does not occur.

There are researchers who claim that OE had a D-system: Wood (2003), Alexiadou (2004) or Ibaraki (2008) to name a few. Wood (2003) argues that OE had DP since there is N-to-D movement of proper names, although there was no dedicated definite article, and demonstratives were DP specifiers.

My position is not far from Wood (2003) and Alexiadou (2004); there was no dedicated definite article and $\mathrm{OE}$ only had demonstratives (Wood (2003)). However, they assume a DP layer with an empty D-slot for OE. Care is needed when we posit invisible or inactive elements in lan- 
guages. Wood (2003) gives a very detailed analysis of word order in $\mathrm{OE}$ nominals and claims that demonstratives, possessives and adjectives are strictly ordered, and then, there must be some functional layers above $\mathrm{NP}$ in $\mathrm{OE}$, although there was no article as such. Thus, when possessive pronouns appear together with other adjectives, possessive pronouns usually precede them. In a similar vein, Ibaraki $(2008,2009)$ argues that the nominal structure in $\mathrm{OE}$ is not much different from that of PDE except the position of possessives. The different distribution of possessives made it possible for demonstratives and possessives to co-occur in OE. However, there are examples of different word orders available for most of the cases. The demonstrative + possessive + adjective + noun order co-existed with the possessive + demonstrative + adjective + noun order (cf. Alexiadou (2004: 41)).

What I would like to say is that the presence of a few pronominal elements before the head nominal and the word order do not give crucial evidence for the presence of a DP layer and, especially, for the presence of a D-head. As I have argued above, the crucial evidence for the presence of a functional category is the presence of syntactic effects which are dependent on the presence of a relevant functional category in a given language.

I conclude that DP was not established as such in OE, based on the absence of syntactic phenomena related to DP such as anaphor binding, a group genitive construction and of-genitive, etc. See Osawa $(2000,2007)$ for further details.

\subsection{From NP to DP}

The task of DP is to identify the referentiality of nominals and turn them into arguments (cf. Abney (1987), Longobardi (1994)). ${ }^{2}$ In the absence of DP, the same task is taken care of by morphological case on the head nouns in OE (cf. Osawa (2000)). Nouns can become arguments if they are casemarked in OE.

As I mentioned before, in a lexical-thematic language, all constituents are thematically related. Then, morphological case is assigned to a thematically related nominal only. Morphological case-marking, which is thematically

\footnotetext{
2 According to the DP analysis (Abney (1987), Longobardi (1994)), nominals in PDE are a projection of a head D. NPs are inherently predicative and cannot occur in argument positions. The task of DP is to identify the referentiality of nominals and turn them into arguments.
} 
motivated, is sufficient for a nominal to become an argument in a lexicalthematic language.

The leveling of inflectional endings had already begun in $\mathrm{OE}$ and by the early Middle English period many $\mathrm{OE}$ inflectional distinctions were lost. Morphological case could not perform the task of identifying the $\mathrm{R}$ (eferential) role of nouns and turning them into arguments any more, and subsequently a functional D-system developed to do the same job in English. Many syntactic phenomena related to DP such as anaphor binding, group genitive constructions were made possible due to this newly emergent functional D.

\subsection{Absence of TP}

It would be better to refer to the non-establishment of a functional T/Isystem in OE. A question of how to analyse a past tense form in $\mathrm{OE}$ arises. Again we need other evidence for the presence of TP (or IP) than temporal suffixes on verbal stems.

The function of $\mathrm{T}$ in PDE is to discharge the $\mathrm{E}$ (vent) role of a verb. Verbs, as well as nominals, have an open position, which must be bound for temporal interpretation. This Event position (E position or $\mathrm{E}$ role) is the hidden argument place for events or situations. In PDE, the binder of this $\mathrm{E}$ position is a functional $\mathrm{T}$. However, the binder of this E position is not limited to a functional $\mathrm{T}$. There are many other devices to bind the E position (see the discussion in section 4). In $\mathrm{OE}$ the binder is provided by temporal affixes attached to verbal stems. The tense morpheme on the verb is only related to giving a semantic temporal location to the event described by the predicate and does not constitute a syntactic functional category TP. Many syntactic effects are due to the presence of TP in the clause structure such as the subject requirement known as the EPP (Extended Projection Principle), modal auxiliaries and do-support. None of them are observed in OE, while all of them are attested in PDE. The absence of these phenomena implies the absence of syntactic TP. The affixation is a purely morphological process with no syntactic effects.

I suggest that the absence of ECM (Exceptional Case Marking) constructions constitutes a good piece of evidence for the absence of TP in OE. Infinitives having a clausal structure are assumed to be an instance of TP. They did not exist in OE. The precursors of PDE infinitives were derived nominals which have case inflections. This follows easily if we assume no TP in OE. In particular, in a lexical-thematic language, ECM constructions are not expected: 
(8) I believe him [to have killed Tom]

In (8) the case of him is checked by a main verb believe, while him receives its thematic role from the lower clause. In the ECM, case is assigned by a thematically unrelated verb. This is not tenable in a lexicalthematic language. For the same reasons, the absence of raising constructions in $\mathrm{OE}$ is easily accounted for. Later, derived nominals developed into clauses due to the emergent $\mathrm{T}$. The demise of case morphology demolished the thematically motivated case system. See Osawa (2003b) and Tanaka (2006) for further discussion. ${ }^{3}$

\section{First Language Acquisition and Diachronic Language Change}

\subsection{Parallels between First Language Acquisition and Language Change}

In this section, I argue that the process of first language acquisition takes the same developmental path as that of diachronic change in terms of functional category emergence.

Not a few of the characteristics attested in earlier English are shared with grammars of children acquiring English at around the two-word stage (the age of 24 months $+/-20 \%$ ):

(9) The properties of first language acquisition at around the twoword stage:

(i) the acquisition of four lexical categories $(\mathrm{N}, \mathrm{V}, \mathrm{A}, \mathrm{P})$ and their projections (NP, VP, AP, PP)

(ii) no D-systems, i.e. the non-acquisition of the morphosyntax of referential determiners such as alan and the and the possessive determiner 's

(iii) no T/I-systems, i.e. the non-acquisition of the morphosyntactic properties associated with T/I: a. do-support, b. modal auxiliaries, c. finite verb forms, d. EPP

(iv) no C-systems, i.e. the non-acquisition of the morphosyntactic properties associated with $\mathrm{C}$ : no complementizers, no Wh-movement

(cf. Klima and Bellugi (1966), Radford (1990, 2000), Clahsen, Eisenbeiss and Penke (1996), Tsimpli (1996))

These facts suggest the lack of functional categories in early child English (aged 18-24 months) (cf. Radford (1990, 2000)). The functional category

\footnotetext{
${ }^{3}$ Concerning the issue of CP emergence, see Michio Hosaka's paper in this series.
} 
systems come into existence after this period.

The child's early grammatical development can be described as the acquisition of grammatical categories (cf. Radford (1990), Tsimpli (1996)). The child's first language development is divided into three main stages:

(i) one-word stage 'acategorial stage' $12 \sim 18$ months

(ii) early multi-word stage 'lexical stage' $18 \sim 24$ months

(iii) later multi-word stage 'functional stage' $24 \sim 30$ months At the one-word stage children begin to associate particular sound sequences with particular concepts. They produce first words. However, at this stage the words produced by children are acategorial, that is, they have no grammatical properties. Children proceed to the two-word (early multi-word) stage, which consists of lexical categories only. The stage involving functional categories in addition to lexical categories comes after this stage.

Based on these facts, I point out that there are strong syntactic parallels between first language acquisition (i.e. ontogeny) and diachronic language change (i.e. phylogeny), and that the same mechanism of functional category emergence is working in both domains. ${ }^{4}$

Look at the examples enumerated below:

(11) Open door/Want car (Stefan 19 months, Radford (1990: 84))

(12) Mommy key

(Gia 20 months, holding mother's key, Bloom (1970))

${ }^{4}$ An anonymous $E L$ reviewer asks why there should be parallels between first language acquisition and diachronic change at all. Some linguistic phenomena like adjective declensions or the absence of auxiliaries, which were observed in OE, are not observed in child data. Why do these differences exist, if there are parallels between ontogeny and phylogeny? For the moment, it is very difficult to give satisfactory answers to the question of what is behind the similarities between ontogeny and phylogeny. Bickerton (1990) and Hurford et al. (1998) refer to the issue of parallelisms between ontogeny and phylogeny. What I claim is not that the two processes, i.e. ontogeny and phylogeny, are completely identical, but that the underlying mechanism of the emergence of functional categories is the same. Child languages are more dependent on pragmatics or context than on grammatical/syntactic decoding and morphology. See the discussion in section 3.3 (cf. Avrutin (2006)). Earlier English was more dependent on morphology. The emergence of functional categories means that more tasks go to syntax. In both domains, syntax encodes more tasks. Therefore, the difference between $\mathrm{OE}$ and child language in adjective declensions is not problematic to my discussion here. The reviewer argues that children properly distinguish main verbs from auxiliaries at the beginning of acquisition, referring to Stromswold (1990). Most of the relevant data discussed in Stromswold (1990) comes from children belonging to the functional stage after the lexical stage. 
(13) Kendall see Kendall

(Kendall 23 months, looking at a picture of herself, Bowerman (1973))

(14) Helen ride (Helen 21 months, Ede and Williamson (1980))

(15) Biscuit gone/Hammer gone/Car gone

(Angharad 22months, Radford (1990: 149))

(16) Wayne not eating it/Wayne not eat it

(Daniel 23 months, Radford (1990: 152))

(17) Go?

(Eve 25 months, Brown and Fraser (1963))

(18) Want [baby talking] (Hayley 20 months, Radford (1990: 121))

(19) Where helicopter? (Stefan 17 months, Radford (1990: 125))

In adult counterparts, determiners, i.e. articles and possessive 's, are needed in (11) and (12). In (13), the second noun Kendall must be expressed in a reflexive form. The examples from (14) to (17) show the lack of TP/IP, and (18) and (19) clearly show that children do not acquire a C-system.

Judging from the data presented, we can say that the overall structure of early child grammars of English is lexical in nature. All structures produced by young children aged 20-24 months are thematic in that every constituent except VPs theta-marks or is theta-marked by its sister constituent.

In the framework of the Minimalist Program, differences between languages are reduced to differences between the features of items belonging to the set of functional categories. This means that languages which consist of lexical categories only lack parametric differences. Although I have referred to English children here, children's early speech is said to be remarkably similar from language to language as well as from child to child. For example, the phenomenon of missing arguments is observed cross-linguistically, regardless of whether the corresponding adult speech allows null subjects (Italian, Spanish) or not (PDE):

(20) I want candy (adult) / Want candy (child)

The child utterance in (20) lacks a subject argument in the subject position of the verb want, while the adult English grammar requires the subject because of the EPP feature of T. In Japanese, the child lacks a subject argument too, as shown below:

(21) Oishii

delicious

'It's delicious.'

(25 months, Slobin (1985: 492))

Its adult counterpart is said to be a so-called pro-drop language. This phenomenon is described by Hyams (1987: 3) as "well-known properties of early language, notably the optionality of lexical subjects and the absence of 
modals and auxiliaries." Hyams (1987) tries to explain this phenomenon as the setting of a pro-drop parameter to a positive value at this stage, regardless of the target grammar, and the later resetting to a negative value. On my hypothesis, child grammars have no T-system, and, assuming that the subject requirement is due to the functional category $\mathrm{T}$, the absence of the subject requirements in child grammars is easily explained.

Variation in word order is also observed cross-linguistically in early child speech. Assuming that fixed argument positions depend on the presence of functional projections in clause structure, prefunctional grammars are thus predicted to allow for word-order possibilities not available in the corresponding target grammars. Then, a given pattern is possible in early child speech, while it is impossible in the corresponding adult speech. TP provides the subject with a fixed position, thus restricting the possibilities of unmarked orders to one. Thus, both pre- and post-verbal subjects have been attested in data from early French (Pierce (1989)) and English (Tsimpli (1996: 149)):

(22) travaille papa works daddy

(23) papa travaille daddy works

(24) cough Christy

Likewise, in adult grammars the object argument appears in a fixed position as a result of its movement to the Spec of AGR-O or the Spec of small v. On the contrary, the early child clause structure renders this derivation impossible because of the absence of the relevant landing site. Thus, objects at this stage are predicted to exhibit a certain variability compared to their adult counterparts. In other words, both OV and VO orders are expected to be cross-linguistically available. Look at the examples from (25) to (27) cited from Tsimpli (1996: 160-174) and (28) from Slobin (1985: 461):

$$
\begin{aligned}
& \text { a. nelo pini (OV) } \\
& \text { water drinks } \\
& \text { b. papu vosisi Atsia (OVS) } \\
& \text { grandad helps Alexia } \\
& \text { c. katai moo (VO) } \\
& \text { holds baby } \\
& \text { (26) yoghurt eat (OV) }
\end{aligned}
$$



a. chapeau chercher $(\mathrm{OV})$
b. papa couper cheveux (SVO)
c. cheveux couper papa (OVS)
d. couper cheveux papa (VOS)
ire ta yo aiai o (VO)
put in $\mathrm{FP}^{5}$ monkey Acc

(French)

(Japanese)

This is taken to be due to the fact that the functional categories, in terms of which the relevant phenomenon is involved, have not emerged. From this follows the absence of parametric differences at the lexical stage of early child speech.

\subsection{Nominal Structure}

If in earlier child English a functional category D is absent, it follows that child grammars have only NPs. This is indeed the case. Nouns or NPs can occur in places where DPs are expected in the corresponding adult English. The non-presence of pre-nominal determiners such as althe has already been shown. The non-acquisition of the genitive determiner 's, which is assumed to be a head determiner D in adult English, is illustrated in (12). However, the following example uttered by Gia is given by Bloom (1970: 93)):

(29) Mommy's

(Gia 20 months, holding mother's key) Interestingly, the child who utters (12) and (29) does not produce Mommy's key. This suggests that this 's form is not a genitive determiner as in adult speech. Maybe, this Mommy's is better analysed as an inseparable nominal NP as a whole, which corresponds to Mama-no 'Mommy's' observed in the Japanese acquisition data at the same stage.

The non-acquisition of the referential properties of nominals is also expected since the binding properties of pronominals are determined by a Dsystem. Indeed, binding is not observed in early child speech as exemplified in (13). This absence is also consistent with the situation observed in OE. Like OE, the case-assigning "dummy" preposition of does not occur in early child speech, either. All the facts suggest that children have not acquired referential properties of pronominals.

\subsection{Maturation versus Continuity}

Other approaches to first language acquisition have been proposed by

${ }^{5}$ FP stands for a sentence final particle. 
many acquisition researchers (cf. Weissenborn (1990, 1992), Boser, Lust, Santelmann and Whitman (1992), Déprez and Pierce (1993), Poeppel and Wexler (1993), Rizzi (1993/1994), Wexler (1994), Hyams (1996), etc.). I will review their approaches briefly and explain why I advocate the socalled maturation theory.

Although the details are different, their assertions are summarised as follows: all principles of Universal Grammar (hereafter UG) and all parameter settings are available from the very beginning of language acquisition; that is, the grammatical constraints and parameter settings are the same for child and adult language. It follows that even at the initial stages of language acquisition, the clause structure is similar to the clause structure of the adult grammar in that both lexical and functional categories and their respective propositions are accessible to the learner and not constrained by maturation. However, parameters are not yet fixed to their target value. Parameter-setting is said to be dependent on the availability of an appropriate set of data referred to as triggering data. These data are distinct from input data in that it is only at a certain stage of language acquisition that their presence in the linguistic input leads to parameters being set to their target value.

Differences between adult and child speech are said to be attributed to external factors, i.e. to developmental delays in domains other than grammatical competence $(=\mathrm{UG})$. Under this hypothesis, some or all functional categories are present in child's grammars from the beginning, prompting the question: why aren't they overtly realised? It has been said that it is due to the child's limited vocabulary or limited memory. For example, contrary to the maturation theory, in Weissenborn (1990) and Boser, Lust, Santelmann, and Whitman (1992), the German child is said to have an IP and a CP already at the two-word stage. ${ }^{6}$ The fact that the child does not use the full CP-structure is due to the complexity of the morphological paradigm of German verbs. According to Weissenborn's (1992) analysis of early null subjects, young children leave out many subjects that are required in the adult counterpart because they have not yet acquired the appropriate pragmatic constraints that hold for null versus overt subjects in adult grammars (cf. Clahsen (1996: xix)).

Contrary to these approaches, I advocate the maturation theory. The

${ }^{6}$ Concerning early child German, see section 4 of Yasuhito Hosaka's paper in this series. 
maturation theory argues that certain grammatical properties are missing from early child grammars until the appearance of the related principles or grammatical categories regulating those properties. These categories and principles are subject to maturation. ${ }^{7}$ This position assumes that maturation affects functional categories (cf. Guilfoyle and Noonan (1988), Tsimpli (1996)). Functional categories are absent in early child grammars from the age of 18 to 24 months because they appear after the early multi-word stage through a process of maturation. This position is not always inconsistent with some of the alternative approaches mentioned above in that UG principles are available to a child from the onset of language acquisition, and these principles constrain possible grammars throughout the language acquisition process.

There are several reasons why I advocate this functional category maturation hypothesis. First, this hypothesis can best account for the crosslinguistic similarities observed in early child grammars. Children's early speech is said to be similar from language to language despite the differences in target languages. If parametric variation is exclusively associated with functional categories, the absence of the kind of parametric variation in adult speech is predicted if we assume that functional categories are lacking in child grammars.

By contrast, in the alternative approaches, the absence of parametric variation is not so easily explained. Within their approaches, the absence of parametric variation from early child grammars is taken to be the result of default feature specification or underspecification of features associated with functional categories. For a parameter to be fixed to its target value,

7 This maturation hypothesis is divided into two different positions: one assumes that maturation affects the Principles of UG (Borer and Wexler (1987)), i.e. "UG-associated" maturation; while the second position assumes that maturation affects functional categories (Guilfoyle and Noonan (1988), Tsimpli (1996)), which is sometimes called the "Structure-building" account. Borer and Wexler (1987) assume that maturation affects certain notions or categories associated with UG. According to this theory, principles of UG are present from the beginning, but specific elements of linguistic knowledge are scheduled to be operative at a later stage. The absence of verbal passives in child grammars is ascribed to the non-availability of the notion of A-chains to children (Borer and Wexler (1987: 141-157)). They argue that early child syntax is more restrictive than adult syntax because it is affected by developmental learning constraints that uniquely characterise child grammars and generate a subset of the representations that are possible in adult grammars. However, the alleged "Optional Infinitives" stage, if it is assumed to exist, means that child syntax is less restrictive since this "Optional Infinitives" stage is not accepted in adult syntax. 
children need to go through a learning process which amounts to matching syntactic features with the appropriate functional category (see Tsimpli (1996: 12-13)). For this learning process, triggering data are necessary.

There is a problem with the notion of default feature specification. Pierce (1989) claims that the Infl-parameter is instantiated in its default value, while the VP-internal parameter is set to the target value right from the start. However, there is no reason given by the proponents of the continuity theory why only some parameters have default values, while others have already been set (see Pierce (1989)). A further important problem with this approach is triggering data in the process of parameter-setting. In this case, the transition from one stage to the next in the acquisition process is determined by the recognition on the part of the child of a set of triggering data. In this approach, parameters in early child speech are not yet fixed to their target value, and parameter-setting is dependent on the availability of an appropriate set of data referred to as triggering data (Tsimpli (1996: 13)). The obvious question follows: why do certain elements but not others serve as triggering data and only at a certain stage, but not at another, given that they are available to the child throughout all stages of development?

In the maturation theory, this problem does not arise since the transition from one stage to the next is determined by inherent maturational factors, i.e. the emergence of new functional categories. ${ }^{8}$

Furthermore, concerning children's pragmatic ability, although children may not acquire an elaborate inference system at this stage, there is research suggesting that children properly make use of discourse knowledge to give a temporal interpretation in Root Infinitives or Optional Infinitives. Sekita (2007) argues that, drawing on the syntax-to-discourse mapping model (Avrutin (2006)), if there are no functional categories, the lexical informa-

${ }^{8}$ An anonymous EL reviewer asks what the exact nature of maturation is. Borer and Wexler (1987: 124) give an example of the maturation of secondary sexual characteristics as an analogy, which do not develop until adolescence. An underlying biological program guides the development. I suggest that since the language faculty is a biological ability akin to walking, children acquire language as a by-product of growing up, simply by being exposed to it (cf. Chomsky (2005: 6)). The child has no conscious knowledge of the muscular coordination which is necessary for walking. Still, his/her muscles develop after birth according to an endogenous schedule. Similarly, the pathway of human development is sensitive to some sort of blueprint of the human being. I propose tentatively that some sort of blueprint for language is transmitted from generation to generation in our species. 
tion is transferred to the information structure by the context in early child speech.

The issue of Optional Infinitives will be discussed in more detail in the next section.

\section{Tense and Aspect}

4.1. Tense and Aspect in First Language Acquisition

Early child grammars at the early multi-word stage have no T/I-system, and thus children do not acquire the morphosyntactic properties associated with T/I such as $d o$-support, modal auxiliaries, EPP, and finite verb forms. The structures produced by English children at this stage typically involve uninflected verb forms and $-i n g-/+(e) n$ forms:

(30) Hayley draw it (Hayley 10 months, Radford (1990: 148))

(31) Doggy barking (Bethan 21 months, Radford (1990: 148))

(32) Tractor broken

(Daniel 23 months, Radford (1990: 149))

It is noteworthy that children frequently use the $\sim i n g / \sim e n$ forms, compared with their sporadic use of other affixes like the regular past (i.e. -ed) and the regular third person singular (i.e. $-s$ ). These $\sim$ ing/ en forms contain aspectual information, as Radford (2000: 8) argues:

(33) The earliest aspectual structures produced by English children typically comprise a 'bare' $+i n g /+n$ participle structure (i.e. a structure containing a progressive/perfect participle but no progressive/perfect be/have auxiliary). For example, (in the Bloom corpus on CHILDES) Alison produces 30 progressive participle structures (including Walking around, Standing up, Peeking Mom$m y$, etc.) none of which contain the progressive auxiliary be.

There is much literature supporting the aspectual status of +ing and +en (cf. Comrie (1976), Dahl (1985), C. Smith (1991)). This means that children are aware of aspectual information before the emergence of TP. This aspect before tense hypothesis is widely accepted by child language researchers (cf. Antinucci and Miller (1976), Olsen and Weinberg (1999), Shirai and Anderson (1995)), although there are opposite views on this issue (cf. Hyams (1996, 2006, 2007), Wexler (1994)). Look at the order of morpheme acquisition: 
(34) The order of morpheme acquisition (Brown (1973: 274))

\section{Order Morpheme}

1. Present Progressive

2.3. Prepositions: in/on

4. Plural dogs

5. Past irregular

6. Possessive

8. Articles
Average Rank (MLU) ${ }^{9}$

2.33

2.50

3.00

6.00

6.33

7.00

Brown (1973: 324) states that "the children do use a small number of state and involuntary verbs rather often, especially want, like, need, know, [...] and they never put these verbs in the progressive." That is to say, the $\sim$ ing form in early child English is consistently used with non-stative verbs without error from the very beginning.

Antinucci and Miller (1976) and Bloom et al. (1980) also argue that early use of tense morphology actually marks aspectual distinctions and therefore that children acquire aspect before tense. According to Antinucci and Miller (1976), the distinction between stative and non-stative verbs is one of the earliest to appear in early child Italian, where the stative/non-stative distinction is a manifestation of situation-type aspect (cf. C. Smith (1991)).

Bloom et al. (1980) have examined four native English-speaking children and have found that two-year-olds always use the non-completive verb play in the (present) progressive, while they use the achievement or completive verb find in the past tense. Bloom et al. (1980) say that past tense indicates telicity, progressive -ing indicates an activity, and simple present tense (identified by 3rd singular $-s$ ) indicates a state. For Bloom et al. (1980) this fact is taken as evidence that the phrasal morphology (in this case, the ing or the $\sim e d$ ) is a marker of lexical aspect. Two-year-old children can therefore make a lexical aspect distinction. ${ }^{10}$

9 MLU stands for Mean Length of Utterance.

${ }^{10}$ Hyams $(2006,2007)$ develops a different analysis from the aspect first hypothesis, claiming that the data she has examined denies any morphological account of aspect first effects. She proposes a different analysis, claiming that in bare verb sentences temporal reference is fully determined by event structure, that is, temporal reference is determined structurally, by the Punctuality Constraint and the Default Anchoring Requirement, in combination with language-specific aspectual properties. Hyams $(2006,2007)$ further claims that this system of temporal interpretation based on event structure may be present in the computation of temporal reference in finite clauses. Her analysis suggests that 
Likewise, Tsimpli (1996: 48, 66) states that temporal specification in early child grammars involves aspectual rather than tense distinctions. She states that -en and -ing forms are aspectual elements that respectively denote the perfective and the imperfective progressive.

The verbs in their bare form are controversial, however. Following Tsimpli (1996: 66), I argue that they also bear aspectual information. All in all, I conclude that children at the early multi-word stage before the emergence of the T/I-category are sensitive to aspect.

Some researchers claim that from the earliest stages, children use their tense morphology correctly and properly distinguish between tense and aspect. Then, they must answer the question of why the syntactic properties related to TP are absent from child data.

The phenomenon of Optional Infinitives (Wexler (1994)) or Root Infinitives (Rizzi (1993/1994)) exists in some languages, for example, English, Dutch, German and French. In these languages, children go through a stage of alternating between finite and non-finite verb forms in root (main) clauses; that is, they optionally produce Root Infinitives (RI). The existence of this stage is alleged to provide support for the presence of TP at the earliest stage.

According to Pierce (1989), French children from around 20 months to 30 months produced both finite and non-finite forms of lexical verbs in main clauses, and these forms had systematically different distributions with respect to the negative morpheme pas. Finite verb forms preceded pas, but if the verb was non-finite, it followed pas:

(35) Pas manger la poupée

not eat-Inf the doll

'The doll does not eat.' (Pierce (1989), Wexler (1994: 309-310))

(36) Elle roule pas

It rolls no

'It does not roll.'

(Guasti (2002: 110))

Wexler (1994: 311-312) argues that these examples clearly indicate that French speaking children at this stage know the finite and non-finite distinction and know that [+finite] verb forms must move to an appropriate functional projection above pas, i.e. to T/I. Wexler concludes (1994: 311-312)

root bare verbs are licensed by aspectual features in the verb. This supports the role of aspectual information in determining the temporal reference in the absence of a tense specification in early child speech. 
that at the optional infinitive stage the child knows that head movement is forced in the finite case, and yet does not know that non-finite verbs cannot appear as main verbs.

The root infinitive stage is a surprising state of affairs. There is no plausible answer to the question: why do children who know the [+/- finite] distinction, since their grammars have T/I projections, not know the rule which disallows non-finite verbs as main verbs?

Furthermore, unlike the finite clauses, Root Infinitives are incompatible with auxiliary verbs (Rizzi (1993/1994: 380ff), Haegeman (1996: 296)). In other words, auxiliaries are absent or not licensed in Root Infinitives. How can this fact be accounted for? As pointed out by Atkinson (1996: 460), one problem with identifying the French examples as infinitival is that -er endings in French are orally indistinguishable from participial forms. Therefore, it is not implausible to analyse these examples as participles. A better example for deciding on the finite or non-finite status is provided by irregular verbs like venir, or voir, the past participles of which are phonologically different from infinitival forms. Wexler (1994: 311) cites eight infinitival examples of -ir verbs whose past participle forms are different from non-finite forms. However, none of those examples co-occur with the negative particle pas, and hence are irrelevant to the issue of the presence of a T/I-node. The simple occurrence of a form such as voir does not provide evidence for the presence (or absence) of a T/I-node.

\subsection{Earlier Tenseless Languages}

It is rather widely accepted that the Indo-European languages had no grammatical category to express tense originally (cf. Kuryłowicz (1964), Lehmann (1974)). Proto-Indo-European's verbal system was originally based on aspect, with a basic contrast between imperfective and perfective. Use of the perfective indicates that the action is assumed to be completed and, as a consequence, imperfective commonly indicates incomplete action. This contrast in aspect by means of affixes on verbs is clearly reflected in the following Vedic examples:

(37) kuvíd asya védat
certainly it he-will-understand
'He will certainly understand it.'

(Rigveda 2.35.2, Lehmann (1974: 107)) In contrast with the perfective form veda 'I know,' which denotes a state resulting from a completed action, this form vedat by means of its affix $-t$ clearly indicates the imperfective meaning. 
As well as aspect, so-called temporal particles also give a temporal interpretation as in example (38):

(38) hòs eide tá $t^{\prime}$ eónta tá $t^{\prime}$ essómena pró who knew those Ptc being those Ptc will-be before $\mathrm{t}^{\prime} \quad$ eónta

Ptc being

'Who knew the things happening now, those that will happen and those that have happened.'

(Iliad I.70. Lehmann (1974: 139))

The past time was indicated by a particle pró, which means 'before', or 'earlier', while the verb eónta is a non-finite form and does not give deictic information.

\subsection{Modern Tenseless Languages}

As discussed in Comrie (1976: 82-84), today in a number of languages there are no specific markers of past versus present tense, although there are markers of aspect: West African languages such as Yoruba and Igbo and Chinese are among them:

(39) Hufei mai shu qu le.

(Mandarin Chinese)

Hufei buy book go perfective.

'Hufei went to buy a book/books.'

Without a grammatical tense system, the relevant languages use other devices to give a temporal interpretation, which will be discussed below.

\subsection{Tense as a Syntactic Category}

What is tense? First, tense refers to the time of the event or state denoted by the verb in relation to some other temporal reference point, usually to the moment of speech (Comrie (1976: 1-2)). Since tense locates the time of a situation relative to the situation of the utterance, tense is described as deictic.

Secondly, the presence of tense is not influenced by the meaning which is inherent in verbs. We cannot imagine the situation where a certain class of verbs cannot have a past tense form because of their inherent meaning.

Thirdly, tense is independent of a speaker's viewpoint, unlike aspect. Tense is related to the time specification in which a certain event takes place. The speaker cannot change the time specification of the event described (except in special cases like rhetorical expressions). Despite this, their role of giving semantic temporal information is limited (cf. N. Smith (1989: 105-106)). 
Tense in PDE plays a more important role as a syntactic category in the clause structure. The function of TP in PDE is to discharge the E(vent) role of a verb, as mentioned in section 2.3. This is the position $E$ (vent) of the thematic grid of the verb. For a proposition to be interpretable, the position $\mathrm{E}$ must be bound somehow, as a tense specification is necessary for a proposition to be truth-evaluable (Higginbotham (1985: 554ff.)).

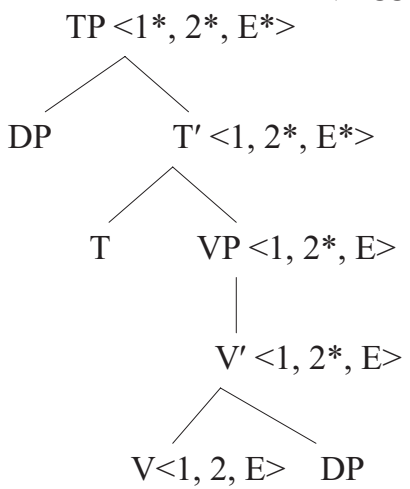

The function of TP is to bind this E-position. In the above tree, the Eposition of the thematic grid of the verb is bound at the point where VP meets Tense/Infl. The asterisk in the angle brackets indicates that the position closes or is discharged.

However, there are a few other ways to bind this E-position: aspect, temporal affixes on verbs, temporal adverbials, and temporal particles can also bind the E-role. Kiparsky (1968) says that tenses in the Indo-European languages derive from adverbs.

\subsection{Aspect}

Tense and aspect are different notions, although they are interrelated. While tense is deictic, aspect is not. Aspect is dependent on a speaker's viewpoint of events or situations. Comrie (1976: 4) states that "it is quite possible for the same speaker to refer to the same situation once with a perfective form, then with an imperfective, without in any way being selfcontradictory."

Unlike tense, aspect is closely related to the meaning of verbs. This is referred to as lexical aspect by C. Smith (1991). Lexical aspect or situation aspect is dependent on the meaning of a verb.

Aspect can be expressed not only lexically, but also synthetically, that is, aspect can be indicated by a composite of verbs, arguments, and adverbials. Thus the forms that specify each aspectual component coexist in a 
sentence.

I claim that in the absence of a syntactic category $\mathrm{T}$, aspect can bind the E-role for temporal specification. This is indeed the case with earlier languages and early child grammars.

4.6. Tense and Aspect: their Differences

We can derive a few interesting consequences from the above.

1. Aspect is present in very early languages both ontogenetically and phylogenetically.

2. Tense category (a functional category) is not universally attested even in Present-day languages.

3. Tense supposedly came later to language.

Consider the following discussions on aspect:

(41) ... the aspectual categories are not language-dependent, but are based in human cognitive abilities. People distinguish between the basic situation types on the basis of their perceptual and cognitive faculties. [...] Children make aspectual distinctions easily, without being taught. $\quad$ (C. Smith (1991: xvii-xviii))

(42) The distinct status of aspect is assumed to be characterized by the following properties; first, it is part of the argument structure of the verb. Secondly, there are no parametric values associated with it. Thirdly, it never projects as an independent head in the clause structure. [...] its [i.e. aspect] presence is required by thematic rather than structural requirements.

(Tsimpli (1996: 76-77))

As Tsimpli (1996: iv) argues, the distinction between these two sets (functional categories/grammatical categories vs. lexical categories/substantive categories) is suggested to be of a cognitive and of a linguistic nature. Based on these discussions I claim that aspect is not a functional category and is close to substantives like nouns and verbs, and it does not constitute a syntactic projection even in PDE.

Let me suggest finally that this claim fits in naturally with the architecture of the human mind adopted by Fodor (1983) and with the account of the central system developed by Relevance theory (Sperber and Wilson (1986)). Substantives are linked to a conceptual slot in the mental lexicon which is assumed to be part of the central cognitive system. Assuming that this conceptual lexicon reflects mental properties which are not purely linguistic, and further that it does not need to refer to language-specific differences in the syntax proper, this mental lexicon is not contained in the 
language module (cf. Tsimpli (1996)).

On the other hand, it is not equally clear that functional categories have a conceptual counterpart in the mental lexicon. There is a systematic correspondence between categories and concepts in the case of substantives, while functional categories lack such a correspondence.

If we assume this discussion, it easily follows that aspect is present in lexical-thematic languages before the emergence of functional categories.

\section{Final Remarks}

In this paper I have shown that there are syntactic parallels between ontogeny and phylogeny in terms of functional category emergence. I have provided syntactic evidence of this parallelism. This is a topic which needs a great deal of future research and the validity of the claim should be tested further. However, the approach discussed in this paper provides some new viewpoints for dealing with diachronic changes and first language acquisition in a unified way.

\section{REFERENCES}

Abney, Steven P. (1987) The English Noun Phrase in Its Sentential Aspect, Doctoral dissertation, MIT.

Alexiadou, Artemis (2004) "On the Development of Possessive Determiners," Diachronic Clues to Synchronic Grammar, ed. by Eric Fuß and Carola Trips, 31-58, John Benjamins, Amsterdam.

Antinucci, Francesco and Ruth Miller (1976) "How Children Talk about What Happened," Journal of Child Language 3, 167-189.

Atkinson, Martin (1996) "Now Hang on a Minute: Some Reflections on Emerging Orthodoxies," Generative Perspectives on Language Acquisition, ed. by Harald Clahsen, 451-485, John Benjamins, Amsterdam.

Avrutin, Sergey (2006) "Weak Syntax," Broca's Region, ed. by Yosef Grodzinsky and Katrin Amunts, 49-62, Oxford University Press, Oxford.

Bickerton, Derek (1990) Language and Species, University of Chicago Press, Chicago.

Bloom, Lois (1970) Language Development: Form and Function in Emerging Grammars, MIT Press, Cambridge, MA.

Bloom, Lois, Karin Lifter and Jeremie Hafitz (1980) "Semantics of Verbs and the Development of Verb Inflection in Child Language," Language 56, 386-412.

Borer, Hagit and Kenneth Wexler (1987) "The Maturaiton of Syntax," Parameter Setting, ed. by Thomas Roeper and Edwin Williams, 123-172, Reidel, 
Dordrecht.

Boser, Katherina, Barbara Lust, Lynn Santelmann and John Whitman (1992) "The Syntax of CP and V2 in Early Child German (ECG): The Strong Continuity Hypothesis," NELS 22, 51-66.

Bowerman, Melissa (1973) Early Syntactic Development: A Cross-linguistic Study with Special Reference to Finnish, Cambridge University Press, Cambridge.

Brown, Roger (1973) A First Language: The Early Stages, Harvard University Press, Cambridge, MA.

Brown, Roger and Colin Fraser (1963) "The Acquisition of Syntax," Verbal Behavior and Learning: Problems and Processes, ed. by Charles Cofer and Barbara Musgrave, 158-201, McGraw-Hill, New York.

Chomsky, Noam (2005) "Three Factors in Language Design," Linguistic Inquiry 36, $1-22$.

Cinque, Guglielmo (1999) Adverbs and Functional Heads, Oxford University Press, Oxford.

Clahsen, Harald, ed. (1996) Generative Perspectives on Language Acquisition, John Benjamins, Amsterdam.

Clahsen, Harald, Sonja Eisenbeiss and Martina Penke (1996) "Lexical Learning in Early Syntactic Development," Generative Perspectives on Language Acquisition, ed. by Harald Clahsen, 129-159, John Benjamins, Amsterdam.

Comrie, Bernard (1976) Aspect, Cambridge University Press, Cambridge.

Dahl, Östen (1985) Tense and Aspect Systems, Blackwell, Oxford.

Déprez, Viviane and Amy Pierce (1993) "Negation and Functional Projections in Early Grammar," Linguistic Inquiry 24, 25-67.

Ede Janet and Jack Williamson (1980) Talking Listening and Learning: The Development of Children's Language, Longman, London.

Fodor, Jerry (1983) The Modularity of Mind, MIT Press, Cambridge, MA.

Gelderen, Elly van (2000) A History of English Reflexive Pronouns: Person, Self and Interpretability, John Benjamins, Amsterdam.

Gelderen, Elly van (2004) Grammaticalization as Economy, John Benjamins, Amsterdam.

Guasti, Teresa Maria (2002) Language Acquisition: The Growth of Grammar, MIT Press, Cambridge, MA.

Guilfoyle Eithne and Máire Noonan (1988) "Functional Categories and Language Acquisition," paper presented at the 13th Annual Boston University Conference on Language Development.

Haegeman, Liliane (1996) "Root Infinitives, Clitics and Truncated Structures," Generative Perspectives on Language Acquisition, ed. by Harald Clahsen, 271-307, John Benjamins, Amsterdam.

Higginbotham, James (1985) "On Semantics," Linguistic Inquiry 16, 547-593.

Hurford, James, Michael Studdert-Kennedy and Chris Knight, eds. (1998) Approaches to the Evolution of Language, Cambridge University Press, Cambridge.

Hyams, Nina (1987) "The Theory of Parameters and Syntactic Development," $\mathrm{Pa}$ rameter Setting, ed. by Thomas Roeper and Edwin Williams, 1-22, Reidel, 
Dordrecht.

Hyams, Nina (1996) "The Underspecification of Functional Categories in Early Grammar," Generative Perspectives on Language Acquisition, ed. by Harald Clahsen, 91-127, John Benjamins, Amsterdam.

Hyams, Nina (2006) “Aspect Matters," Proceedings of the Inaugural Conference on Generative Approaches to Language Acquisition-North America (GALANA), University of Connecticut Occasional Papers in Linguistics 4, 1-18.

Hyams, Nina (2007) "Aspectual Effects on Interpretation in Early Grammar," Language Acquisition 14, 231-268.

Ibaraki, Seishirou (2008) "Eigoshi ni Okeru Meisikunai Youso no Tougoteki Ichi (Syntactic Positions within Nominal Phrases in the History of English)," paper presented at the 25th Conference of Modern English Association.

Ibaraki, Seishirou (2009) "The Development of Determiner System in the History of English," English Linguistics 26, 67-95.

Kiparsky, Paul (1968) "Tense and Mood in Indo-European Syntax," Foundations of Language 4, 30-57.

Klaeber, Frederick ed. (1950) Beowulf and the Fight at Finnsburg, Heath, Lexington.

Klima, Edward, S. and Ursula Bellugi (1966) "Syntactic Regularities in the Speech of Children," Psycholinguistic Papers, ed. by John Lyons and Roger Julian Wales, 183-207, Edinburgh University Press, Edinburgh.

Kuryłowicz, Jerzy (1964) The Inflectional Categories of Indo-European, Carl Winter, Heidelberg.

Lehmann, Winfred, P. (1974) Proto-Indo-European Syntax, University of Texas Press, Austin and London.

Longobardi, Giuseppe (1994) "Reference and Proper Names: A Theory of N-Movement in Syntax and Logical Form," Linguistic Inquiry 25, 609-665.

Muysken, Pieter (2008) Functional Categories, Cambridge University Press, Cambridge.

Olsen, Mari Broman and Amy Weinberg (1999) "Innateness and the Acquisition of Grammatical Aspect via Lexical Aspect," Proceedings of the 23rd Annual Boston University Conference on Language Development, 529-540, Cascadilla Press, Somerville, MA.

Ono, Shigeru and Toshio Nakao (1980) Eigoshi I (History of English I), Taishukan, Tokyo.

Osawa, Fuyo (2000) "The Historical Emergence of DP in English," English Linguistics $17,51-79$.

Osawa, Fuyo (2003a) "Syntactic Parallels between Ontogeny and Phylogeny," Lingua $113,3-47$.

Osawa, Fuyo (2003b) "The Rise of IPs in the History of English," Historical Linguistics 2001: Selected Papers from the 15th International Conference on Historical Linguistics, Melbourne, 13-17 August 2001, ed. by Barry Blake and Kate Burridge, 321-337, John Benjamins, Amsterdam.

Osawa, Fuyo (2007) "The Emergence of DP from a Perspective of Ontogeny and Phylogeny," Nominal Determination: Typology, Context Constraints, and His- 
torical Emergence, ed. by Elisabeth Stark, Elisabeth Leiss and Werner Abraham, 311-337, John Benjamins, Amsterdam.

Pierce, Amy (1989) On the Emergence of Syntax: A Crosslinguistic Study, Doctoral dissertation, MIT.

Poeppel, David and Kenneth Wexler (1993) "The Full Competence Hypothesis of Clause Structure in Early German," Language 69, 1-33.

Radford, Andrew (1990) Syntactic Theory and the Acquisition of English Syntax, Blackwell, Oxford.

Radford, Andrew (2000) "Children in Search of Perfection: Towards a Minimalist Model of Acquisition," ms., University of Essex. <http://privatewww.essex. ac.uk/ radford/PapersPublications/perfection.htm>

Rizzi, Luigi (1993/1994) "Some Notes on Linguistic Theory and Language Development: The Case of Root Infinitives," Language Acquisition 3, 371-394.

Sekita, Makoto (2007) "Time, Syntax and Discourse: The Time Specification of Child Root Infinitives," MA Thesis, University College London.

Shirai Yasuhiro and Roger Anderson (1995) "The Acquisition of Tense-Aspect Morphology: A Prototype Account," Language 71, 743-762.

Slobin, Dan (1985) The Crosslinguistic Study of Language Acquisition, Volume 1: The Data, Erlbaum, Hillsdale, NJ.

Smith, Carlota (1991) The Parameter of Aspect, Kluwer, Dordrecht.

Smith, Neil (1989) The Twitter Machine: Reflections on Language, Blackwell, Oxford.

Sperber, Dan and Deirdre Wilson (1986) Relevance: Communication and Cognition, Blackwell, Oxford.

Stromswold, Karin (1990) Learnability and the Acquisition of Auxiliaries, Doctoral dissertation, MIT.

Tanaka, Tomoyuki (2006) "Hiteikeisetsu ni Okeru Kinouhanchu no Syutsugen (The Rise of Functional Categories in Nonfinite Clauses)," paper presented at the 24th Conference of the English Linguistic Society of Japan.

Tsimpli, Ianthi-Maria (1996) The Prefunctional Stage of Language Acquisition: A Crosslinguistic Study, Garland, New York.

Weissenborn, Jürgen (1990) "Functional Categories and Verb Movement in Early German: The Acquisition of German Syntax Reconsidered," Spracherwerb und Grammatik: Linguistische Untersuchungen zum Erwerb von Syntax und Morphologie (Linguistische Berichte, Special Issue 3), ed. by Monika Rothweiler, 190-224, Westdeutscher Verlag, Opladen.

Weissenborn, Jürgen (1992) "Null Subjects in Early Grammars: Implications for Parameter-setting Theories," Theoretical Issues in Language Acquisition: Continuity and Change in Development, ed. by Jürgen Weissenborn, Helen Goodluck and Thomas Roeper, 269-299, Erlbaum, Hillsdale, NJ.

Wexler, Kenneth (1994) "Optional Infinitives, Head Movement and the Economy of Derivations," Verb Movement, ed. by David Lightfoot and Norbert Hornstein, 305-350, Cambridge University Press, Cambridge.

Wood, Johanna (2003) Definiteness and Number: Determiner Phrase and Number 
Phrase in the History of English, Doctoral dissertation, Arizona State University.

[received April 20 2009, accepted July 28 2009]

Department of English

Hosei University

2-17-1 Fujimi, Chiyoda-ku

Tokyo 102-8160

e-mail: fos@kjps.net 